\title{
Strengthening social capital of urban community during COVID-19 disaster
}

\author{
Dwi Kristanti ${ }^{1}$, Edison Edison ${ }^{2}$, Mohammad Kus Yunanto $^{3}$, Alfiandri Alfiandri ${ }^{2}$, Diah Siti Utari ${ }^{4}$, Tri Samnuzulsari ${ }^{5}$, \\ Dhani Akbar ${ }^{6}$, Suyito Suyito ${ }^{7}$, Emmy Solina ${ }^{5}$, and Wayu Eko Yudiatmaja ${ }^{2 *}$ \\ ${ }^{1}$ Department of Public Administration, Open University, SouthTangerang, Indonesia \\ ${ }^{2}$ Department of Public Administration, University of Maritim Raja Ali Haji, Tanjungpinang, Indonesia \\ ${ }^{3}$ College of Administrative Sciences, Yogyakarta, Indonesia, Yogyakarta, Indonesia \\ ${ }^{4}$ Department of Public Administration, Stisipol Raja Haji, Tanjungpinang, Indonesia \\ ${ }^{5}$ Department of Sociology, University of Maritim Raja Ali Haji, Tanjungpinang, Indonesia \\ ${ }^{6}$ Department of International Relations, University of Maritim Raja Ali Haji, Tanjungpinang, Indonesia. \\ ${ }^{7}$ Faculty of Applied Social Sciences, University of Sultan Zainal Abidin (UniSZA), Trengganu, Malaysia
}

\begin{abstract}
COVID-19 disaster has destroyed many facets of societal and economic circumstances. However, it remains a crucial debate how the effect of COVID-19 on community social capital. This study aims to examine the relationship between a community's risk perception on COVID-19 and social capital. In addition, we also investigate the mediating role of social collectivism in the association. This research used a survey approach by performing an online questionnaire. Data were gathered from 156 respondents at the residence in an urban community in Sukoharjo, Central Java. A partial-least square structural equation modeling (PLS-SEM) was applied to analyze the data. The results show that social capital enhances during COVID 19 because of the increasing risk perceptions on COVID-19 and social collectivism. The impact of risk perceptions on social capital is mediated by social collectivism. The present study adds our understanding of social capital at the time of the COVID-19 outbreak, especially what factors drive it. The research also has practical implications for the government and urban community to anticipate risks of COVID-19 by enhancing social capital and collectivism.
\end{abstract}

\section{Introduction}

Since March 2020, Indonesia has officially been attacked by the Novel Corona Virus (COVID-19) disaster. COVID-19 has been recognized as a national disaster because of the significant effect of the COVID-19 on community health and well-being. Although the government has shown serious commitment and effort to beat COVID-19, the pandemic has not been left until now. Instead, the COVID-19 has gone, the spread of the virus becomes exceptionally uncontrollable. Based on the data of the COVID-19 task force, there were 2,072,867 people infected by the COVID-19, and 56,317 people died by June $25^{\text {th }}, 2021$ [1]. These numbers grew threefold than the beginning of the year.

The COVID-19 brings many impacts on human life. The social and economic effects of COVID-19 have become worst and massive. Suryahadi et al. reported that household expenditure decreased during COVID-19 because of various restrictions of economic activities in many regions in Indonesia. These problems contribute to an increase in the number of poverties in Indonesia [2]. COVID-19 also disrupts the social life of people around the world. Because of many restriction policies, many people can close interact and communicate than before. As a consequence, social bonding declines during the COVID-19 outbreak.

Many people avoid the impact of COVID-19 risk by using a variety of strategies. One of the strategies is to reinforce social capital collectivism. The people realize that they cannot face COVID-19 alone. If the COVID-19 and self-isolated infect them, they need the other and vice versa to fulfill their utilities because there are many forbidden copied during their sick. The people with COVID-19 also need others to strengthen them emotionally and psychologically. The COVID-19 can also increase social collectivism. If the persons are attacked by COVID-19, many people who have sympathy and empathy intentionally tend to help them. The effort to help others is ordinarily delivered sincerely and genuinely. In other words, the increasing social capital and collectivism can be influenced by COVID-19 risks.

Previous studies have shown the importance of social capital during a disaster [3, 4]. Social capital is considered as the community's strength in facing a disease. Diverse dimensions of social capital, such as trust, norms, and networks, are highly believed to predict social cohesion in the time of disaster. Although several studies have sought

\footnotetext{
*Corresponding author: wayuguci@umrah.ac.id
} 
the impact of COVID-19 on economic and social life, the research highlighting what factors affect social capital during COVID-19 is still rare. Much of the study sheds light on natural disasters in portraying social capital, such as earthquakes, floods, tsunami, and volcanic eruptions [5]. Therefore, we need an obvious explanation of how social capital in the era of the COVID-19 disaster.

To fill these research gaps, this study explicitly seeks the association between community's risk perception on COVID-19, social collectivism, and social capital of urban communities in Indonesia. The present research contributes to the current literature in three routes. First, this study analyses the factors determining social capital during COVID-19. Second, we also elucidate the mediating role of social collectivism in the impact of COVID-19 risk perceptions. Lastly, instead of investigating rural communities recognized as high social capital by past studies [3], this work focuses on the urban community in Indonesia.

The structure of this paper is proposed in four sections. In the first part, we highlight the theoretical underpinnings of this study. This section clearly explains the concept used in this study--COVID-19 risk perceptions, social collectivism, and social capital. It is followed by the relationship among the variables, hypothetical statements, and research model. The second section contains methodological issues of the study, covering research method and instrument, sampling, and analytical strategy. The key results of the study are placed in the next section. It also includes the discussion and explanation about the data. Finally, the conclusion provides a summary of the research, including its key findings.

\subsection{Theoretical Framework}

\subsubsection{Risk Perception on COVID-19, Social Collectivism, and Social Capital}

The concept of risk perception is applied to investigate why people take (or do not take) precautions against external threats. To effectively communicate risk and build increased catastrophe risk mitigation techniques, it is necessary to understand risk perception [6]. In the context of COVID-19, individuals who have a higher perception of the risk of the coronavirus affect the way they act. If the perception of the possibility of being exposed to COVID-19 is small, people will tend to ignore health protocols. Public disobedience to health protocols and public distrust of the pandemic tend to have a negative impact on the high spread of COVID-19 cases.

Social collectivism is understood as a set of attitudes, beliefs, behavioral goals, and behaviors associated with solidarity and concern for others [7]. Social collectivism is the antithesis of individualism. It is related to the expected movement of the people socially connected in which they enable to develop social relationships intensively in the community. The process of social collectivism extensively generates added value for common interests, such as fulfilling general needs. Social collectivism can be directed to social actions in the community, specifically helping each other, working together, and social charity, strongly required in disaster.

Social capital refers to a series of informal norms and values collectively owned by the community facilitating cooperation and coordination into society [3]. Social capital becomes an important aspect in the time of the COVID-19 pandemic in Indonesia. Indonesian people are accustomed to living communally, both formally and informally. The group is one of the crucial social capital in Indonesia. The power of groups can encourage solidarity for problem-solving, including the corona disaster. Group participation is required to build collective strength against the COVID-19 outbreak.

Most scholars regard that social collectivism and social capital are similar. However, social capital is quietly different from social collectivism. If social capital is directly implemented in real action, social collectivism is only on the idea and artificial support. Social collectivism is underpinned by cooperation, social ties, and mutual respect. Individuals who are aware of the member of their community will improve community social capital. In sum, social collectivism is an antecedent of social capital. It cannot exist without social collectivism.

\subsubsection{The Relationship among Studied Variables}

This paper assumes that the three latent variables, risk perception on COVID-19, social collectivism, and social capital, are connected. Risk perceptions on COVID-19 positively influence social collectivism. The COVID-19 risk perception is related to the impact of COVID-19 in human life, such as economic, social, and psychological effects. In the economic aspect, the people infected by the COVID-19 have a high vulnerability to the loss of their job and income. They potentially become impoverished because of COVID-19. In terms of the social dimension, the people should apply physical and social distancing to comply with health protocol, implying the people are entirely separated from their social environment.

On the other hand, the people infected by the COVID19 should be self-isolated. It means that they are also detached from their social life. In the end, it can make people more stressed and mentally pressure. All risks make the people have a similar sense that the COVID-19 is dangerous for their humanity. The feeling makes the people more connected and develops social collectivism, mainly for the people who are ever infected by the COVID-19 [8, 9]. Thus, risk perceptions on COVID-19 will enhance community social collectivism (Hypothesis $1)$.

The perceptions of COVID-19 risk tend to care with others because it can be a serious impact on the infected people. In addition, individuals also realize that COVID19 are a danger for not infected people if the infected people do not follow health protocol, especially staying at home. Those infected ordinarily will get sick and cannot carry out their activities normally, such as working, cooking, and praying. The neighbors voluntarily will help provide daily needs of infected people, such as groceries or some foods, medicines, and vitamins, to get well soon 
[10]. The people are willing to help infected people because of two reasons, respectively; it is to help infected people quickly recover and prevent the spreading of the virus. Furthermore, the neighbor will help the people who are losing their job because of COVID-19 by providing meals and donations. Therefore, COVID-19 risk perceptions will improve social capital (Hypothesis 2).

The community with high social collectivism ordinarily also has high social capital $[11,12]$. Thereby, social collectivism can positively enhance social capital (Hypothesis 3). The COVID-19 risk perception can influence a community's social capital through social collectivism. High community social collectivism [13, 14]. Therefore, social collectivism positively mediates the relationship between COVID-19 risk perceptions and social capital (Hypothesis 4).

\subsection{Hypotheses and Research Model}

This research has three variables, predicted (risk perceptions on COVID-19), mediated (social collectivism), and dependent variable (social capital). From the explanation of theoretical framework and relationships among studied variables, the hypotheses of this research can be formulated as follows: H1: Risk perceptions on COVID-19 have a significant impact on social collectivism, H2: Risk perceptions on COVID-19 have a significant impact on social capital, H3: Social collectivism has a significant impact on social capital, and H4: The effect of risk perceptions on COVID-19 is mediated by social collectivism.

Based on these hypotheses, the research model can be drawn in Fig. 1.

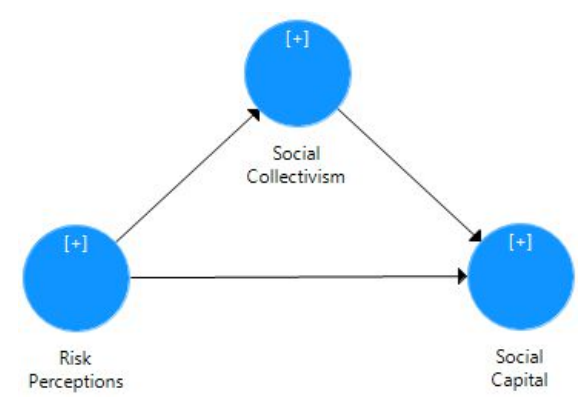

Fig. 1. Research Model

\section{Methods}

This research used quantitative inquiry to achieve the study purpose. A survey approach was applied in this research. This study examined the relationships between risk perceptions on COVID-19, social collectivism, and social capital during the COVID-19 pandemic.

\subsection{Sampling Procedure}

This study used a cross-sectional survey approach. A nonprobability sampling procedure was applied in this research. Data were gathered using a self-administered questionnaire. Because of the COVID-19 pandemic condition, we distributed the questionnaire through an online form (google docs) in the WhatsApp Group (WAG) of the residence. The participants came from households of Korpri residence at Gayam, Sukoharjo, Central Java. One hundred eighty respondents participated in filling the questionnaire. After screening the data, only 156 questionnaires were valid and complete.

The demographic characteristics of the respondents were quietly different. The majority of the respondents were female $(58 \%)$ than male $(42 \%)$. Most of the respondents attained a Bachelor's degree (56), senior high school $(42 \%)$, and graduates $(2 \%)$, indicating the respondents were well educated. In terms of occupation, there was a mother household (35\%), civil servant (26\%), teacher $(13 \%)$, entrepreneur $(12 \%)$, student $(10 \%)$, and doctor or health workers (4\%). Around 3\% of respondents had monthly income greater than IDR $10.000 .000,52 \%$ IDR $\quad 5.000 .000-10.000 .000, \quad 38 \%$ IDR $3.000 .000-$ 5.000 .000 , and following $2 \%$ less than IDR 3.0000.000.

\subsection{Measures}

The constructs included in the questionnaire consisted of three variables, namely risk perceptions, social collectivism, and social capital. The constructs of this research were measured using tested and validated items developed by prior studies. Risk perceptions were assessed utilizing six items expanded by de Bruin [15]. The sample statement for the item was, "I worried about the loss of my job because of COVID-19". Social collectivism was evaluated using five items developed by Yamaguchi [16]. The sample statement for the construct was, "I would like to support my neighbor infected by COVID-19". Social capital was rated using six items built up by Onyx \& Bullen [17] and validated by Yudiatmaja et al. $[3,18]$. The sample statement for the construct was, "Participated local emergency action during COVID-19". All items were assessed using a five-point Likert's scale, 1 (strongly disagree), 2 (disagree), 3 (neutral), 4 (agree), and 5 (strongly agree).

\subsection{Statistical Analysis}

After completing the questionnaire, data in this research were analyzed employing partial least square structural equation modeling (PLS-SEM) [19]. It was used because of two reasons related to the usage of PLS. First, although the respondent of this research was only 156 persons, it was adequate to process with PLS-SEM because the minimum standard of the respondent was 100 . Second, the use of PLS-SEM was quietly suitable for non-parametric statistics with non-normality data [20]. A SmartPLS software was performed as a research tool. Using SmartPLS, the data were analyzed using the PLS algorithm and bootstrapping techniques. PLS algorithm was applied to check the validity and reliability of the data. To test the studied hypotheses, this research employed bootstrapping using 5000 resample. The decision was made by identifying path coefficient or beta $(\beta), t$-value, and $p$-value. 


\section{Results and Discussion}

\subsection{Measurement Model}

Measurement model assessment is aimed to inspect the validity and reliability of the data. Validity was assessed using convergent and discriminant validity. Convergent validity is evaluated by identifying the loading factor of the items and the average variance extracted (AVE). Based on the data in Table 1, it can see that all items have a loading factor exceeding 0.70 ; thereby, all items are valid and acceptable [21]. To assess reliability, composite (CR) and construct reliability. CR was evaluated by identifying $\mathrm{CR}$ value, and construct reliability of all constructs was inspected by checking Cronbach's alpha $(\alpha)$. The results indicate that CR and Cronbach's alpha is greater than 0.70 , implying the data are reliable and acceptable [22].

Table 1. Validity and Reliability

\begin{tabular}{|c|c|c|c|c|}
\hline $\begin{array}{c}\text { Variable/Ite } \\
\mathbf{m}\end{array}$ & Item & $\begin{array}{c}\text { Loadin } \\
\mathbf{g}\end{array}$ & CR & AVE \\
\hline & RPC1 & 0.876 & & \\
Risk & RPC2 & 0.853 & & \\
Perceptions & RPC3 & 0.903 & 0.953 & 0.772 \\
& RPC4 & 0.888 & & \\
$\alpha=0.914$ & RPC5 & 0.891 & & \\
& RPC6 & 0.870 & & \\
\hline \multirow{2}{*}{ Social } & SOC1 & 0.876 & & \\
Collectivism & SOC2 & 0.888 & & \\
& SOC3 & 0.904 & 0.949 & \\
$\alpha=0.933$ & SOC4 & 0.889 & & \\
& SOC5 & 0.882 & & \\
\hline & SCP1 & 0.818 & & \\
Social & SCP2 & 0.823 & & \\
Capital & SCP3 & 0.819 & \multirow{2}{*}{0.936} & 0.709 \\
& SCP4 & 0.879 & & \\
$\alpha=0.918$ & SCP5 & 0.856 & & \\
& SCP6 & 0.855 & & \\
\hline \multicolumn{5}{|l}{}
\end{tabular}

In assessing discriminant validity, we apply Fornell \& Larcker's (FL) and HTMT criteria. Table 2 exhibits that all square roots of AVE (in bold and diagonal) are higher than the association of respective rows and columns [23]. Accordingly, discriminant validity was fulfilled by the measurement model. HTMT criterion also was employed to estimate discriminant validity. As suggested by Kline, the threshold of HTMT values is 0.90 [24]. As can be seen in Table 2, the values of HTMT are lower than 0.90, indicating adequate discriminant validity.

Table 2. Discriminant Validity

\begin{tabular}{|c|c|c|c|}
\hline $\begin{array}{c}\text { FL Criterion } \\
\text { Construct }\end{array}$ & $\mathbf{1}$ & $\mathbf{2}$ & $\mathbf{3}$ \\
\hline Risk Perception & $\mathbf{0 . 8 7 9}$ & & \\
Social Collectivism & 0.685 & $\mathbf{0 . 8 8 8}$ & \\
Social Capital & 0.633 & 0.662 & $\mathbf{0 . 8 4 2}$ \\
\hline HTMT Criterion & 1 & 2 & 3 \\
Construct & & & \\
\hline Risk Perception & & & \\
Social Collectivism & $\mathbf{0 . 7 2 6}$ & $\mathbf{0 . 7 0 8}$ & \\
Social Capital & $\mathbf{0 . 6 7 3}$ & $\mathbf{0}$ \\
\hline
\end{tabular}

\subsection{Structural Model}

The structural model was assessed after the measurement model is fit. To test the multicollinearity, the values of all variance inflation factors (VIF) before testing the hypotheses. Based on the result of SmartPLS, VIF values are little than a rule of thumb, 3. Therefore, the measurement model is free from multicollinearity issues.

Table 3 and Fig. 2 summarize the results of hypothesis testing. The findings show that the community's risk perceptions on COVID-19 positively and significantly affect social collectivism $(\beta=0.685, t=11.38, p<0.001)$, and $\mathrm{H} 1$ is supported by the data. Community's risk perceptions on COVID-19 also positively and significantly impact social capital $(\beta=0.338, t=3.817, p$ $<0.001$ ) and H2 is accepted. Community's social collectivism positively and significantly influences social capital $(\beta=0.431, t=5.131, p<0.001)$ and $\mathrm{H} 3$ is accepted. Lastly, the effect of community's risk perceptions on COVID-19 on social capital is mediated by social collectivism $(\beta=0.295, t=4.430, p<0.001)$, and $\mathrm{H} 4$ is supported.

Table 3. Hypotheses Testing

\begin{tabular}{|c|c|c|c|c|}
\hline Path & $\boldsymbol{\beta}$ & $\begin{array}{c}\text { T } \\
\text { Value }\end{array}$ & Sig. & Decision \\
\hline RPC -> SOC & 0.685 & 11.38 & $* * *$ & Supported \\
RPC -> SCP & 0.338 & 3.817 & $* * *$ & Supported \\
SOC - > SCP & 0.431 & 5.131 & $* * *$ & Supported \\
RPC -> SOC -> SCP & 0.295 & 4.430 & $* * *$ & Supported \\
\hline
\end{tabular}

Note: Sig. ${ }^{* * *}=p<0.001$

The predictive power of the model is identified by analyzing R-square. Fig. 2 also reveals the R-square of social collectivism and social capital. The data show that $\mathrm{R}$-square for social collectivism is 0.469 , followed by social capital 0.500 . The results indicate that the variance of social collectivism was shaped about $46.9 \%$ by risk perceptions. In addition, about $50 \%$ of the variance of risk perceptions and social collectivism can establish social capital.

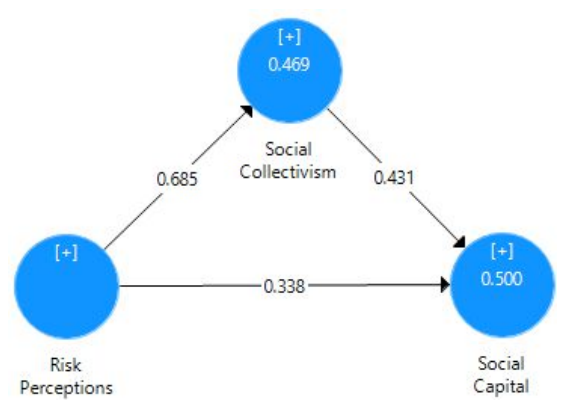

Fig. 2. Structural Model

\subsection{Discussions}

This work shed light on the impact of the community's risk perceptions on COVID-19 and social collectivism on social capital. After processing the data, we reveal that there is a positive and significant relationship between risk perceptions on COVID-19 and social collectivism. 
There is a significant influence of the community's risk perceptions on COVID-19 in predicting social collectivism. The findings show the positive connection between the urban community's COVID-19 risk perceptions and social collectivism. Residents realizing COVID-19 risks can encourage social collectivism in their community. The result confirms the study conducted by Germani et al. stressing individualism and collectivism in reducing perceived risks of COVID-19 [25].

The research claims that COVID-19 risk perceptions positively and significantly influence social capital. The individuals understanding the impact of COVID-19 on their life tend to strengthen social capital. It is applied because they realize the significant effect of COVID-19 on the social, economic, psychological, and health of persons. Then, they have a consciousness to help others or neighbor through various actions, such as providing some foods, medicine, and vitamins. If the efforts are conducted by many people in the community, it can enhance community social capital.

This investigation notes that social collectivism has an essential role in strengthening social capital. There are five statements of social collectivism, such as "I would like to support my neighbor infected by COVID-19", "I would like to assist my neighbor infected by COVID-19", and "I feel the pain felt by my neighbors infected by COVID-19", who has been identified to increase social capital. Espirit of the corps of the urban community enhance social capital during COVID-19. The findings are supported by previous research pointing out the emergence of collectivism on social capital [26].

Moreover, this research also highlights the mediating effect of social collectivism. Social capitalism can be a mediator in the relationship between COVID-19 risk perceptions and social capital. Social collectivism can improve the impact of the community's perceptions on COVID-19 risk. The positive relationship between risk perceptions on COVID-19 and community social capital is partially mediated by social collectivism. The result corroborates previous research predicting individualism and collectivism on social capital in OECD member countries [27].

The findings of this study have several implications for the study and practice of social capital. Regarding the theory, our research contributes to the debate of social capital during COVID-19 in an urban community. We consider risk perceptions on COVID-19 and social collectivism as predictors of the increasing social capital at the time of the COVID-19 pandemic. These variables may lead to a better understanding of how social capital can work during a disaster. This study also provides a valuable suggestion for the government in socially handling COVID-19 impact on society. The government should offer intensive understanding to the community about the significant effect and risks of COVID-19 not only to human health and economy but also to social circumstances.

\section{Conclusion}

In this study, we investigate the effect of the COVID-19 disaster on the social capital of the urban community and whether the impact is mediated by social collectivism. Four hypotheses related to the connections among variables are tested. The findings of the research support all hypotheses by which community's risk perceptions on COVID-19 and social collectivism can predict social capital. This study also finds the mediating role of social collectivism in associating risk perceptions on COVID-19 and social capital. Theoretically, the current research enriches the study of social capital by recognizing COVID-19 risk perceptions and social collectivism of urban communities. Practically, our findings can be worthy policy recommendations to the government in reducing the impact of the COVID-19 pandemic by strengthening the community's social capital.

\section{References}

1. "Covid19.go.id," [Online]. Available: https://covid19.go.id/. (2021)

2. A. Suryahadi, R. Al Izzati, and D. Suryadarma, "Estimating the impact of Covid-19 on poverty in Indonesia," Bull. Indonesia. Econ. Stud., 56, 2, 175192 (2020).

3. W. E. Yudiatmaja, Y. Yudithia, T. Samnuzulsari, S. Suyito, E. Edison, Social capital of local communities in the water resources management: An insight from Kepulauan Riau," in IOP Conference Series: Materials Science and Engineering, 771, 1 (2020)

4. N. E. Ganapati, "Downsides of social capital for women during disaster recovery: Toward a more critical approach," Adm. Soc., 45, 1, 72-96 (2013).

5. S. Partelow, "Social capital and community disaster resilience: post-earthquake tourism recovery on Gili Trawangan, Indonesia," Sustain. Sci., 16, 1, 203-220 (2021).

6. I. A. Rana, S. S. Bhatti, A. B. Aslam, A. Jamshed, J. Ahmad, and A. A. Shah, "COVID-19 risk perception and coping mechanisms: Does gender make a difference?" Int. J. Disaster Risk Reduct., 55, 1-10 (2021).

7. C. H. Hui, "Measurement of individualismcollectivism," J. Res. Pers., 22, 17-36 (1988).

8. M. Yıldırım, E. Geçer, and Ö. Akgül, "The impacts of vulnerability, perceived risk, and fear on preventive behaviors against COVID-19," Psychol. Heal. Med., 26, 1, 35-43 (2021).

9. S. Suyito and N. A. Ghani, "The Pattern of People Participation of Island Society of Dendun Village, Bintan Regency," Policy Soc. Rev., 1, 1, 1-6 (2021).

10. Y. Yudithia, E. Edison, D. Kristanti, T. Samnuzulsari, S. Suyito, and W. E. Yudiatmaja, "Evaluating the Impact of Technological Adoption Policy for Rural Coastal Communities," E3S Web Conf., 202, 1-7 (2020).

11. J. Allik and A. Realo, "Individualism-collectivism and social capital," J. Cross. Cult. Psychol., 35, 1, 29-49 (2004). 
12. D. Kristanti et al., "Network governance in addressing climate change: a case study of the Asian Cities Climate Change Resilience Network (ACCCRN) in Indonesia," IOP Conf. Ser. Earth Environ. Sci., 724, 1, 012091 (2021).

13. N. Plohl and B. Musil, "Modeling compliance with COVID-19 prevention guidelines: the critical role of trust in science," Psychol. Heal. Med., 26, 1, 1-12 (2021).

14. G. G. Alrubaiee, T. A. H. Al-Qalah, and M. S. A. AlAawar, "Knowledge, attitudes, anxiety, and preventive behaviors towards COVID-19 among health care providers in Yemen: An online crosssectional survey," BMC Public Health, 20, 1, 1-11 (2020).

15. W. B. de Bruin, "Age differences in COVID-19 risk perceptions and mental health: Evidence from a national U.S. survey conducted in March 2020," $J$. Gerontol. B. Psychol. Sci. Soc. Sci., 76, 2, e24-e29, (2021).

16. S. Yamaguchi, "Collectivism among the Japanese: A perspective from the self," in individualism and collectivism: Theory, method, and applications, no. Cross-cultural research and methodology series, U. Kim, H. C. Triandis, C. Kagitcibasi, S.-C. Choi, and G. Yoon, Eds. Newbury Park, CA: Sage, 18, 175-188 (1994).

17. J. Onyx and P. Bullen, "Measuring social capital in five communities," J. Appl. Behav. Sci., 36, 1, 23-42 (2000).

18. W. E. Yudiatmaja et al., "Reducing solid waste through waste banks: an empirical study in Kepulauan Riau, Indonesia," IOP Conf. Ser. Earth Environ. Sci., 755, 1, 012076 (2021).
19. I. Y. Prastya, S. D. Meilinda, R. Sulistiowati, A. Alfiandri, and W. E. Yudiatmaja, "Application of SEM: an analysis of Depok City's website," IOP Conf. Ser. Mater. Sci. Eng., 1088, 1, 012028 (2021).

20. J. F. Hair, G. T. M. Hult, C. M. Ringle, and M. Sarstedt, A primer on partial least squares structural equation modeling (PLS-SEM), 2nd Ed. Thousand Oaks, CA: Sage Publications (2017).

21. J. F. Hair, J. J. Risher, M. Sarstedt, and C. M. Ringle, "When to use and how to report the results of PLSSEM," Eur. Bus. Rev., 31, 1, 2-24 (2019).

22. W. W. Chin, "How to write up and report PLS analyses," in Handbook of partial least squares, V. E. Vinzi, W. W. Chin, J. Henseler, and H. Wang, Eds. Berlin: Springer, 655-690 (2010).

23. C. Fornell and D. F. Larcker, "Evaluating structural equation models with unobservable variables and measurement error," J. Mark. Res., 18, 1, 39-50 (1981).

24. R. B. Kline, Principles and practice of structural equation modeling, 4th Ed. New York: The Guilford Press (2015).

25. A. Germani, L. Buratta, E. Delvecchio, and C. Mazzeschi, "Emerging adults and covid-19: The role of individualism-collectivism on perceived risks and psychological maladjustment," Int. J. Environ. Res. Public Health, 17, 10, 1-15 (2020).

26. W. E. Yudiatmaja et al., "Social policy on the rural coastal communities: Why the implementation fails?," E3S Web Conf., 232, 1-7 (2021).

27. K.-I. Yoon, "The cultural effects of individualism and collectivism on social capital," Int. Area Rev., 13, 2, 187-212 (2010). 